\title{
Antimalarials-Are They Safe to Use in Children?
}

\author{
James E. Rasmussen, M.D.
}

University of Michigan Medical School, Department of Dermatology and Pediatrics, Ann Arbor, MI

\begin{abstract}
From 1963 to the present, many reviews of antimalarials for use in dermatology have mentioned the special sensitivity of children to these drugs. Fatal reactions have been limited to accidental or intentional overdosage and two instances of IM injection. While $1 \mathrm{gm}$ of chloroquine can produce fatal reaction in very young children, analysis of published and unpublished cases show that adults exhibit a similar sensitivity when compared on a $\mathrm{mg} / \mathrm{kg}$ basis. This information should encourage a physician to use antimalarials where appropriate, but special precaution should be taken to prevent poisoning
\end{abstract}

Antimalarials (AM) are not commonly used in the treatment of children with skin disease. There are, however, several situations in which AM may be most useful (1-6). Isaacson, Elgart, and Turner list over 15 conditions in which antimalarials may be of some therapeutic benefit (3). Of these, discoid lupus erythematosus and polymorphus light eruption occur with some frequency in children. In addition, Isaacson et al. note that antimalarials have been anecdotally reported to be effective in scleroderma, disseminated granuloma annulare, sarcoid and epidermolysis bullosa, conditions that are also seen occasionally in the pediatric population. There are, of course, other nondermatologic conditions for which antimalarials play a substantial part in therapy. There are numerous reviews attesting to the efficacy of antimalarials in the treatment of rheumatoid arthritis. Antimalarials are still recommended for the prophylaxis and treatment of malaria for both travelers and those who are indigenous to the malaria belts of the world (7). In addition, many authors consider quinacrine to be the treatment of choice for giardiasis, which is a not uncommon enteric parasitic infection of children and young adults $(8,9)$. Finally, the optical isomer of quinine - quinidine - is occasionally used for the treatment of cardiac arrhythmias in children (10).
Although I do not use antimalarials commonly in my pediatric practice, I was aware that there are definite indications for their use in the population and have prescribed them many times without significant adverse reaction. Consequently I have been surprised to read, during the past four years, that many authors consider antimalarials contraindicated in the treatment of children with skin disease (1-6). Four reviews in the past two years mentioned that antimalarials are exceptionally toxic in children (3$6)$, and two of them have concluded that these drugs are contraindicated for use in this population $(3,6)$. I was even more surprised to find that this position was not a new one, but had been mentioned in reviews of antimalarials since 1963. At that time, Rees and Maibach noted that choloroquine was exceptionally toxic in children and that deaths had occurred from as little as $75 \mathrm{mg}$ (1). In addition, Sams in his 1976 review of antimalarials came to a similar conclusion, suggesting that they are contraindicated in children (2).

Because of this paradox-many dermatologists considering antimalarials contraindicated, but other physicians using them for parasitic diseases, rheumatoid arthritis, and a diversity of cutaneous conditions, etc. - I conducted a literature review on this subject and present these results to you. 
Many antimalarials, such as quinacrine, chloroquine, and hydroxychloroquine, have a 4-amino quinoline as their basic nucleus (Fig, 1) (1-6). The first member of this group to be used in the treatment of disease was quinine, which has a well-known history in the prevention and therapy of malaria. In 1894 Payne described the effectiveness of quinine in the treatment of lupus erythematosus. Other antimalarials were synthesized by German biochemists during and after World War I, which caused interruption of normal sources of supply of quinine. Quinacrine (Atabrine and others) and chloroquine (Aralen and others) were the results of these efforts. Further modifications such as hydroxychloroquine (Plaquenil) were developed in the 1950s and soon became commonly used in the treatment of several connective tissue diseases such as lupus erythematosus and rheumatoid arthritis.

There is no evidence suggesting that children have an increased incidence of subacute and chronic toxicity for antimalarials. Nearly all reports focus on accidental or intentional overdosage. Cann and Verhulst were the first to report fatal poisonings from antimalarials in children (11). These 3 fatal cases occurred in 1-3-year-old children who had taken approximately $1-3.5$ grams of chloroquine orally. Toxic symptoms appeared 1 to 3 hours later and consisted of convulsions, apnea, and cardiac arrest. Similar groups of 1-2 children continued to be published during the mid and late 1960s (12-15). Most of the poisonings were due to chloroquine, but at least one occurred after the oral ingestion of quinine (15). In 1974, DeMaio and Henry published a general review of chloroquine poisoning (16). These authors searched the files of the Armed Forces Institute of Pathology for all fatal cases of chloroquine poisoning and detailed 27 case reports. Of this group, 6 were children ranging in age from 11 months to 4

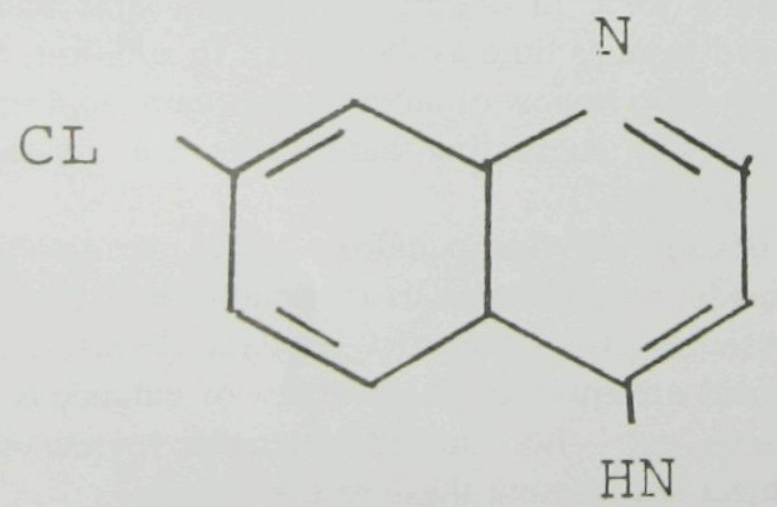

Figure 1. Nucleus of many antimalarials. years. In 3 of the cases, the amount of the drug ingested was unknown, and in the other 3 it ranged from 1 to 2.5 grams. The data available for toxic reactions in the adults in this series indicated that they succumbed to a dose ranging from as few as 10 chloroquine tablets, to approximately 50 . Based on this information, the authors conclude that "children .... appear to be especially sensitive to this drug. " If, however, the number of tablets necessary to produce a toxic reaction in children is compared to that of adults on a tablet or $\mathrm{mg} / \mathrm{kg}$ basis, then this disparity ceases to exist. A 2-year-old child (average weight 14 kilograms) succumbed to $1 \mathrm{gm}$ of chloroquine for a lethal dose of $70 \mathrm{mg} / \mathrm{kg}$, while a minimum of ten $500 \mathrm{mg}$ tablets was needed to produce a fatal result in adult servicemen (average weight 80 kilograms) for a lethal dose of $60 \mathrm{mg} / \mathrm{kg}$.

From 1974 until the present time, poisonings from antimalarials continue to be reported, usually from accidental or intentional overdosage (12-19). There are, however, two examples where chloroquine had been used therapeutically with a fatal outcome (1920). These reports described the intramuscular injection of chloroquine for the treatment of malaria in very young children.

In addition to these published case reports, there are 4 unpublished reports contained in the FDA's toxicology files (21). In these situations, the patients ranged in age from 2 to 17 years, with a minimum toxic dose being $2 \mathrm{gm}$ of chloroquine. One patient in this series was 17 years of age and took an unknown number of hydroxychloroquine tablets.

There are certainly many more examples of toxic reaction to orally ingested antimalarials, but these patients are usually blended in with general reviews of poisoning $(22,23)$. Specific data about drug dose, age of the patient, etc. are usually not given.

Toxic reactions to antimalarials occur quite rapidly after overdose. In part, this is because this group of drugs is rapidly and completely absorbed in the upper portion of the gastrointestinal tract. Nausea and vomiting are common early symptoms and are also seen commonly in children and adults who have taken otherwise safe, therapeutic doses. Several studies suggest that younger children are more susceptable to gastric irritation from antimalarials than are older children $(7,24)$. More advanced cases of poisoning resemble examples of salicylism with tinnitus and vertigo being common symptoms. As poisoning progresses, generalized seizures occur. followed by cardiac and respiratory arrest. Appar- 
ently the fatal effects of AM are in major part related to their ability to depress myocardial excitability.

There is no specific antidote for antimalarial overdose, but immediate gastric emesis and lavage would seem most appropriate. Peritoneal dialysis has been used in one childhood poisoning, but without pronounced beneficial effect (18).

\section{REFERENCES}

1. Rees RB, Maibach H. Chloroquine-a review of reactions and dermatologic indications. Arch Dermatol 1963;88:280-286.

2. Sams WM Jr. Chloroquine: its therapeutic use in photosensitive eruption. Int J Dermatol 1976;15:99-111.

3. Isaacson D, Elgart M, Turner ML. Anti-malarials in dermatology. Int J Dermatol 1982;21:379-395.

4. Koranda FC. Antimalarials. J Am Acad Dermatol 1981;4:650-655.

5. Tanenbaum L, Tuffanelli DL. Antimalarial agents. Arch Dermatol 1980;116:587-591.

6. Logan WS. Antimalarials. Prog Dermatol 1980;14:16.

7. Lal H. A comparative trial of oral chloroquine and oral co-trimoxazole in vivax malaria in children. Am J Trop Med Hyg 1982;31:438-440.

8. Drugs for parasitic infections. Med Lett Drugs Ther 1979;21:105-108.

9. Wolfe MS. Giardiasis. Pediatr Clin North Am 1979:26:295-307.

10. Szefler SJ, Pieroni DR, Gingell RL, Shen DD. Rapid elimination of quinidine in pediatric patients. Pediatrics 1982;70:370-375

11. Cann HM, Verhulst HL. Fatal acute poisoning in children. Pediatrics 1961;27:95-98.

12. Markowitz HA, McGinley JM. Chloroquine poisoning in a child. JAMA 1964;189:950-951.

13. Kiel FW. Chloroquine suicide. JAMA 1964;190:398401.

14. Casson JW, Barringer ML, Jones RE. Fatal chloroquine ingestion. Pediatrics 1967;40:449-451

15. Conway CF. Fatal quinine poisoning. Med J Aust 1967:1:604-605

16. DiMaio VJM, Henry LD. Chloroquine poisoning. South Med 1974;67:1031-1034.

17. Taylor P, Edelsten A, Hughes IA. A case of quinine self-poisoning in a boy. Arch Dis Child 1980;55:478479

18. McCann WP, Pemmisohn R, Palmisano PA. Fatal chloroquine poisoning in a child: experience with peritoneal dialysis. Pediatrics 1975;55:536-537.

19. Gupta DK, Sharma LK. Acute chloroquine toxicity in infants. Indian J Pediatr 1980;17:309-310.

20. Tuboru-Metzger AF. Chemotherapy of malaria. $\mathrm{Br}$ Med J 1964;1:1378-1381.

21. Information on file; supplied through the courtesy of Professional Services Division, Winthrop Laboratories, 90 Park Avenue, New York NY 10016.

22. Broibo NO. Accidental poisoning in children in Uganda. Br Med J 1969;4:601-602

23. Irey NS, Fraide RC. Evaluation of deaths from drug overdosage. Am J Clin Pathol 1974;61:778-784.

24. Craft JC, Murphy T, Nelson JD. Furazolidone and quinacrine. Am J Dis Child 1981;135:164-166. 
This document is a scanned copy of a printed document. No warranty is given about the accuracy of the copy. Users should refer to the original published version of the material. 